\title{
Topical lidocaine improves conditions for laryngeal mask airway insertion
}

\section{La lidocaïne topique améliore les conditions d'insertion du masque laryngé}

\author{
Chih-Fang Changchien, MD • Hung-Shu Chen, MD - Shao-Wei Hsieh, MD • \\ Ping-Heng Tan, MD, PhD • Victor Chia-Hsiang Lin, MD • Chien-Cheng Liu, MD • \\ Ping-Hsin Liu, MD $\cdot$ Kuo-Chuan Hung, MD
}

Received: 18 August 2009/Accepted: 1 February 2010/Published online: 12 February 2010

(C) Canadian Anesthesiologists' Society 2010

\begin{abstract}
Purpose We hypothesized that optimal laryngeal mask airway $\left(L M A^{T M}\right)$ insertion conditions might be achieved with topical lidocaine and a smaller dose of propofol. In this study, insertion conditions after topical lidocaine $40 \mathrm{mg}$ followed by propofol $2 \mathrm{mg} \cdot \mathrm{kg}^{-1}$ were compared with propofol $2 \mathrm{mg} \cdot \mathrm{kg}^{-1}$ or propofol $3 \mathrm{mg} \cdot \mathrm{kg}^{-1}$ alone.

Methods Ninety patients were recruited for this randomized prospective double-blind study. One group received four sprays of topical lidocaine $(40 \mathrm{mg})$ over the posterior pharyngeal wall followed by propofol $2 \mathrm{mg} \cdot \mathrm{kg}^{-1}$ (Group 2PL; $n=30$ ). The other two groups received four sprays of 0.9\% normal saline followed by propofol $2 \mathrm{mg} \cdot \mathrm{kg}^{-1}$ (Group $2 P ; n=30$ ) or by propofol $3 \mathrm{mg} \cdot \mathrm{kg}^{-1}$ (Group 3P; $n=30$ ). The frequency of optimal insertion conditions (successful insertion at the first attempt without adverse responses) and side effects were recorded.

Results The frequency of optimal insertion conditions was greater in Group 2PL (20/30, 67\%) and Group 3P (22/ $30,73 \%)$ than in Group $2 P(11 / 20,37 \%)(P=0.009)$. In Group 3P, the mean blood pressure was lower than in the other groups prior to LMA-Classic ${ }^{T M}$ insertion $(P=0.003)$ but was similar after insertion. The incidence
\end{abstract}

C.-F. Changchien, MD · H.-S. Chen, MD - S.-W. Hsieh, MD · P.-H. Tan, MD, PhD - C.-C. Liu, MD - P.-H. Liu, MD .

K.-C. Hung, MD ( $)$

Department of Anesthesiology, E-DA Hospital, I-Shou University, No.1, Yi-Da Road, Chia-Shu Tsuen, Yan-Chao

Shiung, Kaohsiung 824, Taiwan

e-mail: billwintw@yahoo.com.tw

V. C.-H. Lin, MD

Department of Urology, E-DA Hospital, I-Shou University, Kaohsiung, Taiwan of apnea was greater in Group 3P patients (17/30, 57\%) than in Group 2P (2/30, 7\%) or Group 2PL patients (1/30, $3 \%)(P<0.001)$.

Conclusion Topical lidocaine $40 \mathrm{mg}$ followed by propofol $2 \mathrm{mg} \cdot \mathrm{kg}^{-1}$ can provide optimal insertion conditions of the LMA-Classic comparable to those of propofol $3 \mathrm{mg} \cdot \mathrm{kg}^{-1}$, with fewer hemodynamic changes and a lower incidence of apnea.

\section{Résumé}

Objectif Nous avons émis l'hypothèse que des conditions optimales d'insertion du masque laryngé $\left(L M A^{T M}\right)$ pourraient être créées grâce à l'utilisation de lidocaïne topique et une dose moindre de propofol. Dans cette étude, nous avons comparé les conditions d'insertion après $40 \mathrm{mg}$ de lidocaïne topique puis $2 \mathrm{mg} \cdot \mathrm{kg}^{-1}$ de propofol, avec $2 \mathrm{mg} \cdot \mathrm{kg}^{-1}$ de propofol ou $3 \mathrm{mg} \cdot \mathrm{kg}^{-1}$ de propofol sans lidocaïne topique.

Méthode Quatre-vingt-dix patients ont été recrutés dans cette étude prospective randomisée à double insu. Un groupe a reçu quatre pulvérisations de lidocaïne topique (40 $\mathrm{mg}$ ) sur la paroi pharyngée postérieure, puis $2 \mathrm{mg} \cdot \mathrm{kg}^{-1}$ de propofol (groupe $2 P L ; n=30$ ). Les deux autres groupes ont reçu quatre pulvérisations de sérum physiologique à $0,9 \%$, puis $2 \mathrm{mg} \cdot \mathrm{kg}^{-1}$ de propofol (groupe $2 P ; n=30$ ) ou $3 \mathrm{mg} \cdot \mathrm{kg}^{-1}$ de propofol (groupe $3 P ; n=30$ ). La fréquence de conditions d'insertion optimales (insertion réussie à la première tentative sans réaction négative) et les effets secondaires ont été enregistrés.

Résultats La fréquence de conditions d'insertion optimales était plus élevée dans le groupe 2PL (20/30, $67 \%)$ et le groupe $3 P(22 / 30,73 \%)$ que dans le groupe $2 P$ $(11 / 30,37 \%)(P=0,009)$. Dans le groupe 3P, la tension 
artérielle moyenne était plus basse que dans les autres groupes avant l'insertion du masque laryngé LMA-Classic ${ }^{T M}$ $(P=0,003)$ mais semblable après l'insertion. L'incidence d'apnée était plus élevée dans le groupe $3 P(17 / 30,57 \%)$ que dans les groupes $2 P(2 / 30,7 \%)$ ou $2 P L(1 / 30,3 \%)$ $(P<0,001)$.

Conclusion L'application de $40 \mathrm{mg}$ de lidocaïne topique suivie par $2 \mathrm{mg} \cdot \mathrm{kg}^{-1}$ de propofol peut créer des conditions optimales pour l'insertion du LMA-Classic. Ces conditions sont comparables à celles obtenues lors de l'administration de $3 \mathrm{mg} \cdot \mathrm{kg}^{-1}$ de propofol, avec moins de changements hémodynamiques et une incidence d'apnée réduite.

The laryngeal mask airway $\left(\mathrm{LMA}^{\mathrm{TM}}\right)$ is widely used during minor or ambulatory surgery in spontaneously breathing patients. Among induction agents, propofol is often used to facilitate LMA insertion because it depresses airway reflexes effectively ${ }^{1}$ and makes early recovery possible. $^{2}$ A propofol dose ranging from 2.5 to $3 \mathrm{mg} \cdot \mathrm{kg}^{-1}$ is recommended for LMA insertion, ${ }^{3}$ but insertion of the device is not always smooth in unpremedicated patients. Larger doses of propofol carry the risk of cardiorespiratory depression. In an effort to improve the insertion conditions without increasing the dose of propofol, short-acting opioids, muscle relaxants, or midazolam may be co-administered with propofol to facilitate LMA insertion. ${ }^{4-6}$

Intravenous lidocaine is known to suppress cough reflexes and reduce cardiovascular responses associated with tracheal intubation. ${ }^{7}$ Its use prior to induction has been reported to improve LMA insertion conditions, ${ }^{8,9}$ but not to reduce propofol requirements. ${ }^{6,9}$ Compared with lidocaine $1.5 \mathrm{mg} \cdot \mathrm{kg}^{-1}$ $i v$, the spraying of topical lidocaine $40 \mathrm{mg}$ over the posterior pharyngeal wall has been shown to result in fewer airway incidents and LMA insertion failures in patients receiving thiopental as the induction agent. ${ }^{10}$ The finding led us to hypothesize that the application of topical lidocaine might effectively reduce the dose of propofol required for smooth LMA insertion. In a double-blind randomized trial to test this hypothesis, we compared the LMA-Classic ${ }^{\mathrm{TM}}$ insertion conditions after the combination of topical lidocaine $40 \mathrm{mg}$ and propofol $2 \mathrm{mg} \cdot \mathrm{kg}^{-1}$ with the insertion conditions of propofol $2 \mathrm{mg} \cdot \mathrm{kg}^{-1}$ or propofol $3 \mathrm{mg} \cdot \mathrm{kg}^{-1}$ alone. We further compared the incidence of apnea and hemodynamic changes during anesthesia induction.

\section{Methods}

This was a randomized prospective double-blind study, and the experimental protocol was approved by the Institutional Ethics Committee of the authors' institution. Written informed consent was obtained from each patient involved in the study. We enrolled 90 American Society of Anesthesiologists (ASA) physical status I-II patients aged 18$65 \mathrm{yr}$ undergoing elective surgery, for whom a laryngeal mask was the airway of choice. Patients were excluded from the study if they had a history of gastroesophageal reflux, a history of allergy to the study drugs, or if they were taking any sedative drugs that would influence the anesthesia induction.

Using a computer-generated table of random numbers managed by one of the authors (V.C.H.L.), the patients were randomly assigned to one of three groups using a sealed envelope in the operating room. One group received two sprays of topical lidocaine (10\% Xylocaine $\left.{ }^{\circledR}\right)$ (AstraZeneca, Sweden) on each side of the posterior pharynx wall (40 mg, $10 \mathrm{mg}$ per spray) three minutes before the induction of anesthesia with propofol $2 \mathrm{mg} \cdot \mathrm{kg}^{-1}$ iv (Group 2PL, $n=30$ ). The other groups were given four sprays of $0.9 \%$ normal saline via an atomizer three minutes prior to propofol $2 \mathrm{mg} \cdot \mathrm{kg}^{-1}$ iv (Group 2P, $n=30$ ) or propofol $3 \mathrm{mg} \cdot \mathrm{kg}^{-1} i v$ (Group 3P, $n=30$ ), respectively. The doses of propofol were calculated based on total body weight. The authors (C.C.L. or P.H.L.) who were not involved in the data collection prepared, covered, administered, or sprayed all study drugs. In three groups, the bolus dose of propofol $\left(2 \mathrm{mg} \cdot \mathrm{kg}^{-1}\right.$ or $3 \mathrm{mg} \cdot \mathrm{kg}^{-1}$ ) was injected intravenously over $30 \mathrm{sec}$. In addition, $2 \%$ lidocaine $1 \mathrm{~mL}$ was mixed with each $20 \mathrm{~mL}$ syringe of propofol to minimize the pain associated with propofol injection. No other opioids, muscle relaxants, or sedatives were given as premedication.

Before the topical lidocaine or $0.9 \%$ normal saline was applied, each patient received lactated Ringer's solution $5 \mathrm{~mL} \cdot \mathrm{kg}^{-1} i v$ and pre-oxygenation with a face mask for five minutes. All patients were monitored throughout the study using electrocardiography, noninvasive blood pressure, pulse oximetry, and capnography. Then the study drugs were given as mentioned above, and oxygen delivery via a face mask was continued until an effective airway was established in all patients with an LMA. One of the investigators (C.F.C.C., H.S.C. or K.C.H.), who was blinded to group allocation and the type of induction technique, recorded the time to loss of consciousness, which was defined as the interval between the end of the propofol injection until the patient reached loss of eyelash reflex and the inability to open the eyes on a verbal command. During induction of anesthesia, the patient received mask ventilation only when an arterial oxygen saturation $<95 \%$ was observed. The same investigator who recorded loss of consciousness inserted the classic laryngeal mask airway (cLMA) (LMA-Classic ${ }^{\text {TM }}$ Laryngeal Mask Company Limited, Seychelles) when loss of consciousness was observed. These individuals (C.F.C.C., H.S.C. or K.C.H.) had inserted the cLMA successfully in more than 200 
patients using a technique described by Brain. ${ }^{11}$ The cLMA was placed on the hard palate with the cuff deflated and aperture anterior, and then it was advanced in a smooth movement using a digital technique. A size 3 cLMA was used in women and a size 4 in men. The author who inserted the cLMA also recorded the occurrence of coughing, gagging, laryngospasm, or body movement. Laryngospasm was defined as the presence of stridor or other evidence of upper airway obstruction that subsided with deepening of anesthesia. The conditions for cLMA insertion were described as "optimal" when there was an absence of coughing, gagging, laryngospasm, or body movement, and when the cLMA was inserted successfully on the first attempt. If it was impossible to open the patients mouth, further attempts were carried out at one-minute intervals, each attempt being preceded by propofol $0.5 \mathrm{mg} \cdot \mathrm{kg}^{-1}$. Also, when the airway reflexes prevented the cLMA insertion or when gross body movement requiring restraint in the patient was noted, an additional dose of propofol $0.5 \mathrm{mg} \cdot \mathrm{kg}^{-1}$ was given.

After cLMA insertion, the correct position of the cLMA was checked by observing the patient's chest expansion and the end-tidal carbon dioxide $\left(\mathrm{ETCO}_{2}\right)$ during spontaneous or assisted breathing. If the cLMA was malpositioned on the first attempt, a further dose of propofol $0.5 \mathrm{mg} \cdot \mathrm{kg}^{-1}$ was given, and another attempt was repeated up to a maximum of four times. However, the conditions during the cLMA insertion were only assessed at the first attempt. If the fourth attempt failed, endotracheal intubation was performed. Apnea was defined as absence of spontaneous breathing for $>30 \mathrm{sec}$ after successful cLMA insertion. If apnea occurred, manual ventilation was applied to maintain an arterial oxygen saturation $>95 \%$ and an $\mathrm{ETCO}_{2}$ level of 35 to $40 \mathrm{mmHg}$ until the return of spontaneous breathing. Noninvasive blood pressure and heart rate were recorded before induction of anesthesia, immediately after loss of consciousness, and one minute after successful cLMA insertion. Clinically significant hypotension was defined as systolic blood pressure (SBP) $<90 \mathrm{mmHg}$ and was treated with $8 \mathrm{mg}$ of intravenous ephedrine. Anesthesia was maintained at 1-2 minimum alveolar anesthetic concentration sevoflurane in 50\% oxygen and 50\% air. At the end of the operation, the cLMA was removed and the patients were transferred to the postanesthesia care unit. A blinded investigator (S.W.H. or P.H.T.) visited all of the patients the morning after surgery to record whether they were satisfied with the induction technique (yes, no) or whether they experienced a sore throat (yes, no).

The primary outcome was the frequency of optimal cLMA insertion conditions. Additional analyses were done on the incidents of side effects (such as coughing, gagging, laryngospasm, body movement, and apnea) and hemodynamic changes during the induction of the anesthesia.
The proportion of optimal LMA insertion conditions following propofol $2.5 \mathrm{mg} \cdot \mathrm{kg}^{-1}$ in unpremedicated patients was reported as $32.5 \% .{ }^{12} \mathrm{We}$ assumed that $25-30 \%$ would be the proportion of optimal insertion conditions following propofol $2 \mathrm{mg} \cdot \mathrm{kg}^{-1}$, and we considered a $>70 \%$ proportion of optimal cLMA insertion conditions to be satisfactory in unpremedicated patients treated with topical lidocaine and propofol $2 \mathrm{mg} \cdot \mathrm{kg}^{-1}$. We needed 24 patients in each group to achieve $80 \%$ power at the $5 \%$ significance level. Considering that there may be dropouts, we decided to recruit 30 patients per group.

Group data are presented as the mean \pm standard deviation (SD), number, or percentage. The Chi square test (with Fisher's exact test when appropriate) was used to compare cLMA insertion conditions or other adverse responses. We analyzed the continuous variables between groups by means of a variance (one-way ANOVA). If a significant difference was detected, a Tukey test was used for post-hoc comparisons. Repeated measures analysis of variance (ANOVA) was used to compare hemodynamic variables within groups. The $P$ value of $<0.05$ was considered significant. Statistical calculations were performed using the statistical package for the Social Sciences, SPSS/ PC Version 10.0 (Chicago, IL, USA).

\section{Results}

Ninety-six patients met the eligibility criteria. Six patients refused to participate and were excluded. Ninety ASA I or II patients undergoing general anesthesia were equally and randomly divided into three groups. All patients completed the standard protocol. The characteristics of patients in the three groups were similar (Table 1). The characteristics of anesthetic induction and cLMA insertion conditions following either topical lidocaine or normal saline co-administration with propofol are shown in Table 2. Group 3P had a shorter time to loss of consciousness and incidence of apnea than the other two groups (Table 2). Group 2P patients required additional propofol more often and had a lower incidence of optimal insertion conditions than subjects in Groups 2PL and 3P. No significant differences were found in the success rate of first attempt insertion across the three groups, and the cLMA was inserted in all patients within two attempts. The frequency of optimal insertion conditions was greater in Group 2PL $(67 \%)$ and Group 3P (73\%) than in Group 2P (37\%) $(P<0.05)$. Apnea occurred frequently in Group $3 \mathrm{P}(57 \%)$, but not in Group 2P (7\%) or Group 2PL $(3 \%)(P<0.001)$. As shown in Table 3, adverse responses, such as coughing, gagging, and body movement were found mainly in Group 2P. Adverse responses during cLMA insertion were similar in Groups 2PL and 3P. 
Table 1 Characteristics of patients

\begin{tabular}{llll}
\hline & $\begin{array}{l}\text { Group 2P } \\
(n=30)\end{array}$ & $\begin{array}{l}\text { Group 2PL } \\
(n=30)\end{array}$ & $\begin{array}{l}\text { Group 3P } \\
(n=30)\end{array}$ \\
\hline Age $(\mathrm{yr})$ & $46.5 \pm 14.7$ & $45.7 \pm 12.7$ & $46.0 \pm 11.7$ \\
Gender $(\mathrm{M} / \mathrm{F})$ & $18 / 12$ & $17 / 13$ & $15 / 15$ \\
Weight $(\mathrm{kg})$ & $62.1 \pm 12.3$ & $64.7 \pm 11.1$ & $63.2 \pm 11.3$ \\
\hline
\end{tabular}

Values are mean \pm standard deviation $(\mathrm{SD})$ or numbers where applicable. Group $2 \mathrm{P}=$ laryngeal mask airway $\left(\mathrm{LMA}^{\mathrm{TM}}\right)$ inserted following propofol $2 \mathrm{mg} \cdot \mathrm{kg}^{-1}$; Group 2PL = LMA inserted following topical lidocaine $40 \mathrm{mg}$ and propofol $2 \mathrm{mg} \cdot \mathrm{kg}^{-1}$; Group $3 \mathrm{P}=\mathrm{LMA}$ inserted following propofol $3 \mathrm{mg} \cdot \mathrm{kg}^{-1}$

Table 2 Characteristics of anesthetic induction and LMA-Classic ${ }^{\mathrm{TM}}$ insertion

\begin{tabular}{lllll}
\hline & $\begin{array}{l}\text { Group 2P } \\
(n=30)\end{array}$ & $\begin{array}{l}\text { Group 2PL } \\
(n=30)\end{array}$ & $\begin{array}{l}\text { Group 3P } \\
(n=30)\end{array}$ \\
\hline Time to loss of consciousness (sec) & $43.0 \pm 18.6^{*}$ & $39.7 \pm 18.6^{*}$ & $34.3 \pm 5.2$ & 0.034 \\
Additional propofol required & $8(27 \%)$ & $2(7 \%)^{\dagger}$ & $2(7 \%)^{\dagger}$ & 0.031 \\
Incidence of apnea & $2(7 \%)^{* *}$ & $1(3 \%)^{* *}$ & $27(90 \%)$ & $<0.001$ \\
First attempt insertion & $26(87 \%)$ & $28(93 \%)$ & $22(73 \%)^{\dagger}$ & 0.69 \\
Optimal insertion conditions & $11(37 \%)$ & $20(67 \%)^{\dagger}$ & 0.009 \\
\hline
\end{tabular}

Values are mean \pm standard deviation (SD) or number of patients (proportion) where applicable. * Denotes $P<0.05$ (Pairwise comparisons between groups) compared with Group 3P. ${ }^{\dagger}$ Denotes $P<0.05$ (Pairwise comparisons between groups) compared with Group $2 \mathrm{P}$; ** Denotes $P<0.001$ (Pairwise comparisons between groups) compared with Group 3P

Group $2 \mathrm{P}=$ laryngeal mask airway $\left(\mathrm{LMA}^{\mathrm{TM}}\right)$ inserted following propofol $2 \mathrm{mg} \cdot \mathrm{kg}^{-1}$; Group $2 \mathrm{PL}=\mathrm{LMA}$ inserted following topical lidocaine $40 \mathrm{mg}$ and propofol $2 \mathrm{mg} \cdot \mathrm{kg}^{-1}$; Group $3 \mathrm{P}=\mathrm{LMA}$ inserted following propofol $3 \mathrm{mg} \cdot \mathrm{kg}^{-1}$

Table 3 Adverse responses during LMA-Classic ${ }^{\mathrm{TM}}$ insertion

\begin{tabular}{lllll}
\hline Adverse responses & $\begin{array}{l}\text { Group 2P } \\
(n=30)\end{array}$ & $\begin{array}{l}\text { Group 2PL } \\
(n=30)\end{array}$ & $\begin{array}{l}\text { Group 3P } \\
(n=30)\end{array}$ & $P$ value overall \\
\hline Coughing & $10(33 \%)$ & $2(7 \%)^{*}$ & $1(3 \%)^{*}$ & 0.001 \\
Gagging & $8(27 \%)$ & $1(3 \%)^{*}$ & $2(7 \%)^{*}$ & 0.012 \\
Laryngospasm & 0 & 0 & $1(3 \%)$ & 0.36 \\
Body movement & $17(57 \%)$ & $5(17 \%)^{*}$ & $7(23 \%)^{*}$ & 0.002 \\
\hline
\end{tabular}

Values are number (proportion). * Denotes $P<0.05$ (Pairwise comparisons between groups) compared with Group 2P

Group $2 \mathrm{P}=$ laryngeal mask airway $\left(\mathrm{LMA}^{\mathrm{TM}}\right)$ inserted following propofol $2 \mathrm{mg} \cdot \mathrm{kg}^{-1}$; Group $2 \mathrm{PL}=\mathrm{LMA}$ inserted following topical lidocaine $40 \mathrm{mg}$ and propofol $2 \mathrm{mg} \cdot \mathrm{kg}^{-1}$; Group $3 \mathrm{P}=\mathrm{LMA}$ inserted following propofol $3 \mathrm{mg} \cdot \mathrm{kg}^{-1}$

Mean blood pressure in the three groups decreased significantly throughout the study period $(P<0.001)$ (Table 4). Group 3P had lower mean blood pressure than the other groups before cLMA insertion $(P<0.05)$, but not one minute after cLMA insertion. Clinically significant hypotension ( $\mathrm{SBP}<90 \mathrm{mmHg}$ ) was found infrequently in all three groups (Group 2P: 1/30; Group 2PL: 4/30; Group 3P: 3/30). Two patients in Group 3P suffered from severe hypotension ( $\mathrm{SBP}<70 \mathrm{mmHg}$ ), and both were treated successfully with ephedrine. No postoperative cardiovascular complications were found in any of our patients.

All patients tolerated the spraying of lidocaine over the posterior pharynx wall well. The number of patients who had a sore throat or were satisfied with the induction techniques was similar in the three groups (Table 5).

\section{Discussion}

The purpose of this study was to evaluate whether optimal LMA insertion conditions could be achieved following a lower dose of propofol in unpremedicated patients receiving topical lidocaine administered as an oropharyngeal spray. Our major finding was that propofol $2 \mathrm{mg} \cdot \mathrm{kg}^{-1}$ preceded by topical lidocaine $40 \mathrm{mg}$ provided optimal LMA insertion conditions as often as propofol $3 \mathrm{mg} \cdot \mathrm{kg}^{-1}$, 
Table 4 Mean blood pressure and heart rate changes during induction of anesthesia

\begin{tabular}{lcccc}
\hline & $\begin{array}{l}\text { Group 2P } \\
(n=30)\end{array}$ & $\begin{array}{l}\text { Group 2PL } \\
(n=30)\end{array}$ & $\begin{array}{l}\text { Group 3P } \\
(n=30)\end{array}$ \\
\hline Mean blood pressure (mmHg) & $105 \pm 18^{\dagger}$ & $99 \pm 19^{\dagger}$ & $99 \pm 15^{\dagger}$ & 0.35 \\
Baseline & $89 \pm 16^{*}$ & $86 \pm 16^{*}$ & $76 \pm 12$ & 0.003 \\
After anesthetic induction & $83 \pm 14$ & $81 \pm 18$ & $79 \pm 13$ & 0.58 \\
1 min after cLMA insertion & $77 \pm 11$ & $73 \pm 13 \pm 12$ & 0.56 \\
Heart rate (beats·min ${ }^{-1}$ ) & $77 \pm 13$ & $74 \pm 10$ & $74 \pm 12$ & 0.44 \\
Baseline & $77 \pm 10$ & $71 \pm 10$ & $76 \pm 12$ & 0.11 \\
After anesthetic induction & min after cLMA insertion & & & \\
\hline
\end{tabular}

Values are mean \pm standard deviation. SD. * Denotes for between-group comparison. ${ }^{\dagger}$ Denotes $P<0.001$ compared with the value recorded after anesthetic induction (within groups). Group $2 \mathrm{P}=$ laryngeal mask airway ( $\mathrm{LMA}^{\mathrm{TM}}$ ) inserted following propofol $2 \mathrm{mg} \cdot \mathrm{kg}^{-1}$; Group $2 \mathrm{PL}=\mathrm{LMA}$ inserted following topical lidocaine $40 \mathrm{mg}$ and propofol $2 \mathrm{mg} \cdot \mathrm{kg}^{-1}$; Group 3P $=\mathrm{LMA}$ inserted following propofol $3 \mathrm{mg} \cdot \mathrm{kg}^{-1}$

Table 5 Postoperative interview

\begin{tabular}{lccc}
\hline & $\begin{array}{l}\text { Group 2P } \\
(n=30)\end{array}$ & $\begin{array}{l}\text { Group 2PL } \\
(n=30)\end{array}$ & $\begin{array}{l}\text { Group 3P } \\
(n=30)\end{array}$ \\
\hline $\begin{array}{l}\text { Postoperative sore throat } \\
\begin{array}{l}\text { Satisfied with induction } \\
\text { technique }\end{array}\end{array}$ & $50(17 \%)$ & $3(10 \%)$ & $2(7 \%)$ \\
\end{tabular}

Values are number of patients (proportion). There were no statistically significant differences between groups. Group $2 \mathrm{P}=$ laryngeal mask airway $\left(\mathrm{LMA}^{\mathrm{TM}}\right)$ inserted following propofol $2 \mathrm{mg} \cdot \mathrm{kg}^{-1}$; Group 2PL = LMA inserted following topical lidocaine $40 \mathrm{mg}$ and propofol $2 \mathrm{mg} \cdot \mathrm{kg}^{-1}$; Group 3P = LMA inserted following propofol $3 \mathrm{mg} \cdot \mathrm{kg}^{-1}$

with fewer hemodynamic changes and a lower incidence of apnea.

Seavell et al. reported the frequency of coughing, gagging, and laryngospasm in their patients receiving thiopental $5 \mathrm{mg} \cdot \mathrm{kg}^{-1}$ and topical lidocaine $40 \mathrm{mg}$ to be $2.2 \%, 28 \%$, and $4.3 \%$, respectively, during LMA insertion, which was comparable with those receiving propofol $2.5 \mathrm{mg} \cdot \mathrm{kg}^{-1} \cdot{ }^{13}$ Propofol is known to suppress both pharyngeal and laryngeal reflexes more effectively than thiopental. ${ }^{1}$ Therefore, we evaluated the effectiveness of using topical lidocaine $40 \mathrm{mg}$ and a lower dose of propofol $\left(2 \mathrm{mg} \cdot \mathrm{kg}^{-1}\right)$ in improving LMA insertion conditions. The conditions we achieved were comparable with those of propofol $3 \mathrm{mg} \cdot \mathrm{kg}^{-1}$. In addition, the finding that body movement was reduced in Group 2PL (17\%) and Group 3P (23\%) compared with that in Group 2P (57\%) suggests that the supplement of topical lidocaine $40 \mathrm{mg}$ can increase patient tolerance of an LMA in the hypopharynx, even though topical lidocaine may not increase anesthetic depth.

To reduce side effects, such as apnea or hypotension, caused possibly by a large dose of propofol and to evaluate the effectiveness of topical lidocaine, a small dose of propofol $2 \mathrm{mg} \cdot \mathrm{kg}^{-1}$, which has been shown to produce loss of response to verbal contact at this dosage, ${ }^{14}$ was administered after applying topical lidocaine $40 \mathrm{mg}$. Although the hemodynamic profile was within clinically acceptable limits in our relatively healthy patients after cLMA insertion, Group 3P had lower mean blood pressure than the other groups prior to cLMA insertion, suggesting that a larger dose of propofol $3 \mathrm{mg} \cdot \mathrm{kg}^{-1}$ should be used carefully. Also, the incidence of apnea was higher in Group 3P $(57 \%)$ than in Group 2PL (3\%). Siddik-Sayyid et al. also reported that the incidence of apnea might reach $84 \%$ after a propofol $3 \mathrm{mg} \cdot \mathrm{kg}^{-1}$ bolus injection. ${ }^{15}$ Based on these findings, a larger dose of propofol may not be advisable if maintenance of a stable hemodynamic profile and rapid resumption of spontaneous breathing are required.

Bapat et al. reported a $66 \%$ frequency of optimal LMA insertion conditions following propofol $2.5 \mathrm{mg} \cdot \mathrm{kg}^{-1}$ and fentanyl $1 \mu \mathrm{g} \cdot \mathrm{kg}^{-1},{ }^{16}$ which is similar to the conditions we found in Group 2PL or Group 3P. Although opioids are frequently used with propofol to improve LMA insertion conditions in clinical practice, ${ }^{17}$ co-administration of both agents may increase the incidence and duration of apnea due to their synergistic effect on respiratory depression. ${ }^{18,19}$ The incidence of apnea may reach $70 \%$ following the use of propofol $2.5 \mathrm{mg} \cdot \mathrm{kg}^{-1}$ alone and $83.3 \%$ following the use of propofol $2.5 \mathrm{mg} \cdot \mathrm{kg}^{-1}$ plus fentanyl $1 \mu \mathrm{g} \cdot \mathrm{kg}^{-1} \cdot{ }^{20}$ Apnea is probably of little consequence when the airway is protected with the LMA. However, since the cLMA, which is commonly used in our institution, may not provide protection against gastric insufflation during positive pressure ventilation, it may be advisable to maintain spontaneous breathing in patients using a cLMA. In addition, the occurrence of apnea may be undesirable during minor or ambulatory surgery wherein spontaneous ventilation is desired with an LMA. Considering that opioids 
may increase the incidence of apnea, we did not coadminister short-acting opioids, such as fentanyl with propofol, in the current study.

The LMA is widely used for airway management and can be inserted blindly into the hypopharynx, which makes successful LMA insertion possible with propofol doses of 2-2.5 mg $\cdot \mathrm{kg}^{-1}$ under unfavourable conditions. ${ }^{17,21}$ Therefore, the success rate of cLMA insertion was high and similar in our three groups. A smaller size LMA may be inserted more easily when the jaw relaxation is not satisfactory. Hui et al. have suggested that the Asian population has a smaller jaw than the Caucasian population for whom the LMA was designed originally; ${ }^{4}$ therefore, in our study, we chose a size 3 cLMA for women and a size 4 for men.

Although there may be systemic absorption of topical lidocaine administered as an oropharyngeal spray, Mostafa et al. ${ }^{22}$ found that the plasma lidocaine concentrations after topical lidocaine $3 \mathrm{mg} \cdot \mathrm{kg}^{-1}\left(0.8 \pm 0.41 \mu \mathrm{g} \cdot \mathrm{mL}^{-1}\right)$ were well below the toxic range $\left(5-9 \mu \mathrm{g} \cdot \mathrm{mL}^{-1}\right)$. We chose to use an even lower dose of topical lidocaine $(40 \mathrm{mg})$ because this dose has been found to be effective in improving LMA insertion conditions. ${ }^{10}$ In addition, the topical effect of lidocaine on the pharyngeal wall lasts from 20 to $40 \mathrm{~min},{ }^{23}$ which may allow the patient to tolerate the LMA in the hypopharynx during the transition from intravenous induction to maintenance with an inhaled agent. ${ }^{24}$

There are several limitations in our study. First, one may argue that spraying topical lidocaine $40 \mathrm{mg}$ over the posterior pharyngeal wall may be uncomfortable and increase patients' anxiety; however, the satisfaction rate in all three groups was high, suggesting that this technique may be acceptable in anesthesia clinical practice. There might be potential bias in the satisfaction rates because patients who consented to be in the study knew their pharynx would be sprayed. Second, the time from administering propofol to cLMA insertion was shorter than that required to achieve the peak effect of propofol (about $1.6 \mathrm{~min}$ ), ${ }^{25}$ which might have led us to underestimate the frequency of optimal cLMA insertion conditions in the three groups.

In conclusion, our study demonstrates that the frequency of optimal LMA insertion conditions achieved by the combination of propofol $2 \mathrm{mg} \cdot \mathrm{kg}^{-1}$ and topical lidocaine $40 \mathrm{mg}$ was comparable to that achieved using propofol $3 \mathrm{mg} \cdot \mathrm{kg}^{-1}$ alone, with greater hemodynamic stability and a lower incidence of apnea.

Acknowledgement The authors are grateful to Hui-Ching Weng, $\mathrm{PhD}$ for her help in statistical analysis.

Financial support None.

Competing interests None declared.

\section{References}

1. McKeating K, Bali IM, Dundee JW. The effects of thiopentone and propofol on upper airway integrity. Anaesthesia 1988; 43: 638-40.

2. Heath PJ, Ogg TW, Gilks WR. Recovery after day-case anaesthesia. A 24-hour comparison of recovery after thiopentone or propofol anaesthesia. Anaesthesia 1990; 45: 911-5.

3. Asai T, Morris $S$. The laryngeal mask airway: its features, effects and role. Can J Anaesth 1994; 41: 930-60.

4. Hui JK, Critchley LA, Karmakar MK, Lam PK. Co-administration of alfentanil-propofol improves laryngeal mask airway insertion compared to fentanyl-propofol. Can J Anesth 2002; 49: 508-12.

5. Chui PT, Cheam $E W$. The use of low-dose mivacurium to facilitate insertion of the laryngeal mask airway. Anaesthesia 1998; 53: 491-5.

6. Gill PS, Shah J, Ogilvy A. Midazolam reduces the dose of propofol required for induction of anaesthesia and laryngeal mask airway insertion. Eur J Anaesthesiol 2001; 18: 166-70.

7. Yukioka H, Yoshimoto N, Nishimura K, Fujimori M. Intravenous lidocaine as a suppressant of coughing during tracheal intubation. Anesth Analg 1985; 64: 1189-92.

8. Baik HJ, Kim YJ, Kim JH. Lidocaine given intravenously improves conditions for laryngeal mask airway insertion during propofol target-controlled infusion. Eur J Anaesthesiol 2009; 26: 377-81.

9. Stoneham MD, Bree SE, Sneyd JR. Facilitation of laryngeal mask insertion. Effects of lignocaine given intravenously before induction with propofol. Anaesthesia 1995; 50: 464-6.

10. Cook TM, Seavell CR, Cox CM. Lignocaine to aid the insertion of the laryngeal mask airway with thiopentone. A comparison between topical and intravenous administration. Anaesthesia 1996; 51: 787-90.

11. Brain AI. The laryngeal mask-a new concept in airway management. Br J Anaesth 1983; 55: 801-5.

12. Lee MP, Kua JS, Chiu WK. The use of remifentanil to facilitate the insertion of the laryngeal mask airway. Anesth Analg 2001; 93: 359-62.

13. Seavell CR, Cook TM, Cox CM. Topical lignocaine and thiopentone for the insertion of a laryngeal mask airway; a comparison with propofol. Anaesthesia 1996; 51: 699-701.

14. Stokes DN, Hutton P. Rate-dependent induction phenomena with propofol: implications for the relative potency of intravenous anesthetics. Anesth Analg 1991; 72: 578-83.

15. Siddik-Sayyid SM, Aouad MT, Taha SK, et al. A comparison of sevoflurane-propofol versus sevoflurane or propofol for laryngeal mask airway insertion in adults. Anesth Analg 2005; 100: 1204-9.

16. Bapat P, Joshi RN, Young E, Jago RH. Comparison of propofol versus thiopentone with midazolam or lidocaine to facilitate laryngeal mask insertion. Can J Anaesth 1996; 43: 564-8.

17. Cheam EW, Chui PT. Randomised double-blind comparison of fentanyl, mivacurium or placebo to facilitate laryngeal mask airway insertion. Anaesthesia 2000; 55: 323-6.

18. Goodman NW, Black AM, Carter JA. Some ventilatory effects of propofol as sole anaesthetic agent. Br J Anaesth 1987; 59: 1497-503.

19. Goyagi T, Tanaka M, Nishikawa T. Fentanyl decreases propofol requirement for laryngeal mask airway insertion. Acta Anaesthesiol Scand 2003; 47: 771-4.

20. Goh PK, Chiu CL, Wang CY, Chan YK, Loo PL. Randomized double-blind comparison of ketamine-propofol, fentanyl-propofol and propofol-saline on haemodynamics and laryngeal mask airway insertion conditions. Anaesth Intensive Care 2005; 33: 223-8. 
21. Blake DW, Dawson P, Donnan G, Bjorksten A. Propofol induction for laryngeal mask airway insertion: dose requirement and cardiorespiratory effects. Anaesth Intensive Care 1992; 20: 479-83.

22. Mostafa SM, Murthy BV, Barrett PJ, McHugh P. Comparison of the effects of topical lignocaine spray applied before or after induction of anaesthesia on the pressor response to direct laryngoscopy and intubation. Eur J Anaesthesiol 1999; 16: 7-10.

23. Kirkpatrick $M B$, Sanders $R V$, Bass JB Jr. Physiologic effects and serum lidocaine concentrations after inhalation of lidocaine from a compressed gas-powered jet nebulizer. Am Rev Respir Dis 1987; 136: 447-9.

24. Lee MC, Absalom AR, Menon DK, Smith HL. Awake insertion of the laryngeal mask airway using topical lidocaine and intravenous remifentanil. Anaesthesia 2006; 61: 32-5.

25. Struys MM, De Smet T, Depoorter B, et al. Comparison of plasma compartment versus two methods for effect compartment-controlled target-controlled infusion for propofol. Anesthesiology 2000; 92: 399-406. 